\section{Psicologia Escolar \\ e Educacional}

\section{RELATO DE PRÁTICAS PROFISSIONAIS}

DOI: http://dx.doi.org/10.1590/2175-35392021247675

Localizador - e247675

\title{
PSICOLOGIA ESCOLAR NA PANDEMIA POR COVID-19: EXPLORANDO POSSIBILIDADES
}

\author{
Carla Silva Fiaes $^{1} \mathbb{D}$; Kelen Daiany Oliveira do Carmo Ribeiro1 ${ }^{\mathbb{D}}$; Mariana Figueiredo Andrade $\mathbb{1}^{\mathbb{D}}$; Marianna

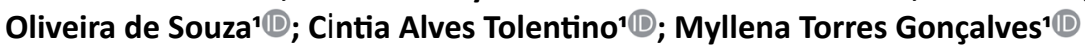

\section{RESUMO}

O período de pandemia devido à Covid-19 reforçou a necessidade de repensar o papel do psicólogo escolar diante dos desafios que o ensino remoto impõe. Este relato de experiência busca revelar as atividades desempenhadas pelas estagiárias de psicologia escolar em uma escola pública do interior da Bahia. As atividades incluíram construção e distribuição de materiais informativos virtuais, projeto de cartas terapêuticas, divulgação de informação em plataformas digitais, além de acolhimento online de casos específicos. O uso das tecnologias de informação e comunicação revelouse como uma estratégia potencial para ação junto ao público adolescente, mas também escancarou as dificuldades de acesso à educação de modo remoto para os alunos de escolas públicas, que foram acirradas durante a pandemia.

Palavras-chave: psicologia escolar; pandemia; escola pública.

\section{School Psychology during the Covid-19 Pandemic: exploring possibilities}

\section{ABSTRACT}

The pandemic period due to Covid-19 reinforced the need to rethink the role of the school psychologist in the face of the challenges that remote education has been imposing. This experience report seeks to reveal the activities performed by school psychology interns at a public school in the Bahia state country. Activities included construction and distribution of virtual informational materials, design of therapeutic letters, dissemination of information about digital platforms, and online hosting of specific cases. The use of information and communication technologies proved to be a potential strategy for action with the adolescent public, but it also opened up the difficulties of remote access to education for students in public schools, which were intensified during the pandemic.

Keywords: school psychology; pandemic; public school.

\section{Psicología Escolar en la Pandemia por Covid-19: explorando posibilidades}

\section{RESUMEN}

El período de pandemia debido a la Covid-19 reforzó la necesidad de repensarse el papel del psicólogo escolar delante de los desafíos que la enseñanza remota impone. Este relato de experiencia busca revelar las actividades desempeñadas por las psicólogas escolar en formación en una escuela pública del interior de Bahía. Las actividades incluyeron construcción y distribución de materiales informativos virtuales, proyecto de cartas terapéuticas, divulgación de información em plataformas digitales, además de acogimiento online de casos específicos. El uso de las tecnologías de información y comunicación se mostró como una estrategia potencial para acción junto al público adolescente, pero también dejó claro las dificultades de acceso a la educación de modo remoto para los alumnos de escuelas públicas, que fueron acerradas durante la pandemia.

Palabras clave: psicología escolar; pandemia; escuela pública.

\footnotetext{
${ }^{1}$ Centro Universitário São Francisco de Barreiras - UNIFASB - Barreiras - Bahia - Brasil; csfiaes@gmail.com; docarmokelen@gmail. com; mariana_fandrade@hotmail.com; mariannasouza59@gmail.com; cyntiatolen@gmail.com; myllena.torres@hotmail.com
} 


\section{INTRODUÇÃO}

A Psicologia Escolar e Educacional tem como preceitos da prática profissional um projeto educacional que promova práticas de formação de qualidade para todos; que enfrente os processos de medicalização e judicialização de educadores e educandos; que lute pela valorização do trabalho do professor e por políticas públicas que possibilitem o desenvolvimento de todos e todas; que estabeleça relações escolares democráticas e que invista na superação dos processos de exclusão e estigmatização social (Conselho Federal de Psicologia, 2013). No entanto, a identidade da/o psicóloga/o no ambiente escolar ainda é alvo de questionamentos e encontra-se em processo de consolidação (Senna \& Almeida, 2015), e o período de pandemia, no qual as escolas precisaram ser fechadas, reforçou a necessidade de repensar o papel desse profissional nesses espaços.

Este trabalho trata-se de um relato do estágio em Psicologia Escolar durante o ano letivo de 2020, que aconteceu de uma maneira diferente do habitual por conta da pandemia do vírus Sars-Cov-2. O estágio foi realizado em uma escola de ensino médio e profissionalizante em um município do interior da Bahia e a equipe de estagiárias foi composta por cinco alunas do curso de Psicologia. A referida instituição conta com 1429 alunos matriculados em seis cursos técnicos: Agropecuária, Informática, Agronegócio, Logística, Comércio e Administração, tendo cada um deles um tempo de duração específico. Os cursos são oferecidos nos três turnos, de acordo com a demanda dos alunos.

No primeiro momento da prática, ainda de modo presencial, foi realizado um levantamento com os alunos e professores com o objetivo de identificar quais demandas estavam presentes em relação ao estágio em Psicologia Escolar, para que a comunidade pudesse expressar suas expectativas e para que pudéssemos traçar um plano de trabalho crítico em relação a elas.

Para acessar essas demandas, foram elaboradas fichas contendo uma lista de temas, tais como automutilação, sexualidade, gênero, autoestima, depressão, ansiedade, dificuldade de estudo e relação professor-aluno, que deveriam ser assinalados de acordo com o interesse de que fossem alvo de intervenção no estágio em Psicologia Escolar. As fichas não continham espaço para dados de identificação do respondente, como nome e idade, e foram distribuídas em todas as turmas dos turnos matutino e vespertino. Na sala dos professores foi instalada uma urna para receber as fichas preenchidas. Um total de 597 alunos preencheram as fichas, o equivalente a $55,3 \%$ do total de matriculados na escola. As fichas dos professores não chegaram a ser coletadas em função da suspensão repentina das aulas em março de 2020, por conta da pandemia de COVID-19 - uma doença causada por um tipo de coronavírus, denominado SARS-CoV-2, que apresenta um espectro clínico que varia de infecções assintomáticas a quadros graves, e que pode levar à morte. A transmissão acontece pelo contato com alguma pessoa infectada, por meio de secreções como gotículas de saliva ou do nariz (Organização Pan-Americana de Saúde [OPAS], 2020).

A suspensão das aulas da rede estadual na Bahia ocorreu pelo decreto № 19.529 de 16 de março de 2020 com o objetivo de evitar o contágio amplo nas escolas, que são ambientes onde há uma grande quantidade de pessoas reunidas. Esse decreto atingiu também o Ensino Superior, impactando as reuniões de supervisão dos estágios. O MEC através de uma série de portarias (Portaria no 343, de 17/03/2020; Portaria no 345, de 19/03/2020; Portaria 395, de 15/04/2020 e Portaria 473 , de $12 / 05 / 2020$ ) orientou que os estágios fossem suspensos até junho, quando passou a flexibilizar a sua realização (Portaria 544, de 16 de junho de 2020). Seguindo as orientações do MEC, o nosso grupo decidiu manter as reuniões através de encontros virtuais com vistas a desenvolver estudos teóricos acerca da Psicologia Escolar. Nesses encontros surgiu a ideia de criar cartilhas de orientação à comunidade escolar no sentido de enfrentamento aos aspectos psicológicas da pandemia.

\section{CARTILHAS}

As cartilhas foram desenvolvidas pelas estagiárias e orientadas pela supervisora de estágio levando em consideração as orientações de entidades nacionais e internacionais, como a FIOCRUZ e a Organização Mundial de Saúde - OMS, além de estudos na área de Psicologia de Emergências e Desastres (Danzmann, Silva, \& Guazina, 2020). O objetivo era oferecer estratégias para a comunidade escolar enfrentar os impactos na saúde mental provocados pela pandemia e oferecer conteúdos científicos em uma linguagem acessível ao grande público.

No projeto das Cartilhas selecionamos os temas mais relevantes identificados nos primeiros contatos presenciais com os alunos para oferecer orientações claras e objetivas sobre como lidar com tais questões em meio a pandemia. Sendo assim, definimos que o primeiro tema a ser abordado nas cartilhas precisava incluir formas de lidar com a ansiedade, uma vez que cerca de $75 \%$ dos alunos assinalaram esse tema nas fichas distribuídas pelas estagiárias.

Foram produzidas ao total quatro cartilhas virtuais ilustradas, com uma média de 13 páginas cada uma, que continham recomendações sobre como lidar com a ansiedade e outras reações emocionais, resolução de conflitos familiares, orientações sobre como identificar e enfrentar o abuso sexual e a violência doméstica, e estratégias para estudar durante a pandemia. Após concluídos, os materiais passaram a ser enviados uma vez por semana aos grupos de whatsapp de professores, alunos e demais profissionais da escola. 
Além da ansiedade, a primeira cartilha abordou as reações emocionais mais frequentes e esperadas durante um período de pandemia, tais como medo de adoecer, de morrer, de transmitir o vírus para outra pessoa ou perder algum ente querido. Ademais, também foram discutidas algumas estratégias de cuidado psíquico nessas situações e sobre quando procurar ajuda. Na segunda foram descritas orientações sobre como evitar conflitos, e também como resolvê-los de forma positiva. A terceira cartilha teve um caráter psicoeducacional sobre os fatores de risco para a violência contra as crianças, adolescentes e mulheres, além de telefones de emergência para contato. Por fim, o último material produzido abordou estratégias práticas para estudar durante a pandemia.

Após o envio das cartilhas, realizamos uma pesquisa de opinião por meio da plataforma Google Forms com o objetivo de receber uma devolutiva da comunidade escolar acerca da qualidade e relevância dos temas abordados, considerando o impacto das informações para cada um dos grupos (professores, funcionários e alunos). Identificamos que o grupo que mais teve acesso às cartilhas foi o dos estudantes, sendo a maioria deles do turno noturno e que o tema apontado como de maior relevância foi "Estratégias para estudar na pandemia", enquanto que os professores distribuíram as escolhas equitativamente entre Ansiedade e Estratégias de Estudo.

\section{CONTATOS NO AMBIENTE VIRTUAL: PROJETO CARTINHAS TERAPÊUTICAS, INSTAGRAM E ATENDIMENTO VIRTUAL}

Diferentemente de alguns modelos observados em algumas cidades e estados no Brasil, a escola pública na qual foi desenvolvido o estágio não contou com políticas de distribuição de tecnologias digitais, como equipamentos e redes de acesso à internet. Considerando essa limitação e a necessidade de manutenção do distanciamento social, foi posto em andamento um segundo projeto, denominado de Cartinhas Terapêuticas, e a criação de uma conta no Instagram para propiciar a comunicação das estagiárias com os alunos e professores de modo assíncrono. $O$ projeto das cartinhas tinha como objetivo fazer uma escuta e acolhimento dos estudantes e da equipe da escola através da escrita. Para envio das cartas foi criado um e-mail com esse fim específico.

O Instagram foi visto como uma ferramenta prática, e o seu sucesso entre os jovens nos levou a escolher essa plataforma para facilitar a divulgação de informações com os alunos. Sendo assim, criamos um perfil e passamos a seguir a página da escola, a partir de então, o perfil da escola passou a replicar todas as nossas publicações. Os materiais postados incluíam os resumos das cartilhas e temas discutidos na supervisão de estágio.

Ao longo do ano letivo, as estagiárias também fizeram escutas e orientação de casos específicos utilizando as recomendações da Resolução 011/2018 do CFP para atendimento online.

\section{CONSIDERAÇÕES FINAIS}

$\mathrm{O}$ isolamento social e a necessidade de combate à pandemia do COVID-19 provocaram novas formas de trabalho, de estudo e de relacionamentos, trazendo impactos enormes em instituições de ensino, em estudantes e em suas famílias.

A produção das cartilhas com diversas temáticas e o uso das tecnologias digitais de informação revelaram-se como um processo inovador para as estagiárias de Psicologia Escolar, uma vez que o período da pandemia inviabilizou o contato próximo com a Comunidade Escolar, dificultando o intercâmbio típico desse tipo de estágio. Por outro lado, o retorno recebido acerca do material produzido no formato de cartilhas, sugere que, ao menos uma parte da comunidade escolar se beneficiou das orientações presentes no material.

Por outro lado, a dificuldade de manter um contato mais intensivo através das plataformas virtuais nos fez refletir sobre os desafios enfrentados pelos alunos de escolas públicas durante a pandemia, nas quais as desigualdades de acesso à educação foram acirradas, conforme também observado por Facci, Silva e Souza (2020). Enquanto boa parte dos alunos das escolas privadas e com nível socioeconômico mais elevado permaneceram estudando por meio de aulas virtuais e demais estratégias, os estudantes da rede pública de ensino, especialmente pela falta de acesso à internet de qualidade, foram, em sua maioria, privados desse direito, ainda que algumas atividades pedagógicas realizadas de modo remoto tenham sido colocadas em prática.

A construção das cartilhas não tinha por objetivo superar essa dificuldade e nem culpabilizar o sujeito pela sua não aprendizagem nesse contexto, mas auxiliá-lo a usar as ferramentas disponíveis. A preferência pela cartilha que abordava a temática estratégias de estudo na pandemia sugere que os alunos estão preocupados com a sua própria aprendizagem, mas que precisam ter acesso a oportunidades equitativas.

Ao longo do período da pandemia de Covid-19, exploramos as alternativas disponíveis para manter o contato com a comunidade escolar e aprendemos também sobre os limites da atuação do profissional de Psicologia. A lei no 13.935/2020, que dispõe sobre a prestação de serviços de psicologia e de serviço social nas redes públicas de educação básica e que ainda aguarda regulamentação do governo federal, consiste em uma estratégia essencial para o acolhimento da comunidade escolar desde já, buscando minimizar os efeitos na saúde mental e possibilitar a aprendizagem, especialmente após o retorno às aulas presenciais.

\section{REFERÊNCIAS}

Lei no 13.935/2019 (11 de dezembro de 2019). Dispõe sobre 
a prestação de serviços de psicologia e de serviço social nas redes públicas de educação básica. Presidência da República. Recuperado de http://www.planalto.gov.br/ ccivil_03/_ato2019-2022/2019/lei/L13935.htm

Decreto no 19.529 (16 de março de 2020). Regulamenta, no Estado da Bahia, as medidas temporárias para enfrentamento da emergência de saúde pública de importância internacional decorrente do coronavírus. Palácio do Governo da Bahia. Recuperado de http://www. legislabahia.ba.gov.br/documentos/decreto-no-19529-de16-de-marco-de-2020

Brasil. Portaria no 343 (1 de março de 2020). Dispõe sobre a substituição das aulas presenciais por aulas em meios digitais enquanto durar a situação de pandemia do Novo Coronavírus - COVID-19. Diário Oficial da União. Ministério da Educação. Seção 1, Edição 53, página 39. Recuperado de https://www.in.gov.br/en/web/dou/-/portaria-n-343de-17-de-marco-de-2020-248564376

Brasil. Portaria no 345 (19 de março de 2020). Altera a Portaria MEC no 343, de 17 de março de 2020. Diário Oficial da União. Ministério da Educação. Seção 1-extra, edição 54-D, página 1. Recuperado de https://www.in.gov.br/ en/web/dou/-/portaria-n-345-de-19-de-marco-de-2020248881422 ? inheritRedirect=true \& redirect $=\% 2 \mathrm{Fweb} \% 2 \mathrm{~F}$ guest\%2Fsearch\%3FqSearch\%3DPortaria\%2520345\%25 20de\%252019\%2520de\%2520mar\%25C3\%25A7o\%2520 de\%25202020

Portaria no 395 (15 de abril de 2020). Prorroga o prazo previsto no $\S 1$ ㅇ do art. 1 o da Portaria no 343, de 17 de março de 2020. Diário Oficial da União. Ministério da Educação. Seção 1, edição 73, página 61. Recuperado de https:// www.in.gov.br/en/web/dou/-/portaria-n-395-de-15-deabril-de-2020-252725131

Portaria $\mathrm{n}$ - 473 (12 de maio de 2020). Prorroga o prazo previsto no $\S 1$ 10 do art. 1o da Portaria no 343, de 17 de março de 2020. Diário Oficial da União. Ministério da Educação. Seção 1, edição 90, página 55. Recuperado de https://www. in.gov.br/en/web/dou/-/portaria-n-473-de-12-de-maiode-2020-256531507?inheritRedirect=true $\&$ redirect $=\% 2 \mathrm{Fw}$
eb\%2Fguest\%2Fsearch\%3FqSearch\%3DPortaria\%2520473 \%252C\%252012\%2520de\%2520maio\%2520de\%25202020

Portaria no 544 (16 de junho de 2020). Dispõe sobre a substituição das aulas presenciais por aulas em meios digitais, enquanto durar a situação de pandemia do novo coronavírus - Covid-19, e revoga as Portarias MEC no 343, de 17 de março de 2020, no 345, de 19 de março de 2020, e no 473, de 12 de maio de 2020. Diário Oficial da União. Ministério da Educação. Seção 1, edição 114, página 62. Recuperado de https://www.in.gov.br/en/web/dou/-/ portaria-n-544-de-16-de-junho-de-2020-261924872

Conselho Federal de Psicologia. (2013). Referências Técnicas para Atuação de Psicólogas(os) na Educação Básica. Brasília: CFP.

Conselho Federal de Psicologia (2018). Resolução $n^{\circ} 11$, de 11 de maio. Regulamenta a prestação de serviços psicológicos realizados por meios de tecnologias da informação e da comunicação. Brasília: CFP.

Danzmann, P. S.; Silva, A. C. P.; Guazina, F. M. N. (2020). Atuação do psicólogo na saúde mental da população diante da pandemia. Journal of Nursing and Health. health. 10(spe), 1-14. Recuperado de https://periodicos.ufpel.edu.br/ojs2/ index.php/enfermagem/article/view/18945/11557

Facci, M. G. D.; Silva, S. M. C.; Souza, M. P. R. (2020). A Psicologia Escolar e Educacional em Tempos de Pandemia (editorial). Psicologia Escolar e Educacional, 24. https:// doi.org/10.1590/2175-3539202001

Organização Pan-Americana de Saúde [OPAS] (2020). Folha informativa COVID-19 - Escritório da OPAS e da OMS no Brasil: Principais Informações. Recuperado de https:// www.paho.org/pt/covid19. Acesso em 20 de dezembro de 2020 às $06 \mathrm{~h} 53 \mathrm{~m}$.

Senna, S. R. C. M.; Almeida, S. F. C. (2015). Formação e atuação do psicólogo escolar da rede pública de ensino do Distrito Federal: Panorama atual e perspectivas futuras. In: Martínez, A. M. (Eds.), Psicologia Escolar e Compromisso Social: novos discursos, novas práticas (3e ed., pp.219-253). Campinas, SP: Editora Alínea. 